\title{
Representações médicas e de gênero na promoção da saúde no climatério/menopausa
}

\author{
Medicals and gender's representations on health \\ promotion in climacteric/menopause
}

Eliana Azevedo Pereira de Mendonça 1

\footnotetext{
1 Departamento de Política Social, Faculdade de Serviço Social. Universidade do Estado do Rio de Janeiro. Rua São Francisco Xavier, 524, Bloco D, sala 8.027. Maracanã, 20550-013, Rio de Janeiro RJ. elianap@uerj.br
}

Abstract The aim of this article is to discuss the limits and the possibilities of educative health practices for the women's health promotion. We should do a critic of the "unilateral communication" and reflect on the need for women to become active parts in this process. Having focusing on an interdisciplinary activity in climacteric women's attention in a health public organization in Rio de Janeiro between 1990-1995, we have observed that the gender's construction had a significant influence in women's daily lives and that most of them had a negative social representation of the menopause. They talked about their fears of the menopause consequences. When we know social representations about menopause, we can access the effectiveness of the discourse about women's physicals and psychological changes during this period life and establish more efficient and communicative exchanges between all the people concerned and the health workers to build new social representations, and help women to express the emotions resulting from the "battle of mind" fought in all their relationships. This would firstly enable them to take an active part in their health promotion, and, secondly improve the way health's workers approach the matter.

Key words Health promotion, Social representations, Educative practices, Gender, Menopause
Resumo Sendo a atenção integral à saúde um desafio às práticas multidisciplinares no âmbito dos serviços públicos de saúde, tomamos como eixo de discussão a crítica à transmissão vertical de informações, o que implica refletir sobre o papel ativo dos sujeitos na abordagem dos fenômenos saúde/doença. Através de práticas educativas na assistência à mulher no climatério em um ambulatório no Rio de Janeiro, observamos que as construções de gênero operam de forma incisiva nas vivências das usuárias. Através de imagens, simbolos e representações expressaram o sentimento de perda em várias direções: insegurança face aos sintomas de natureza física e psicológica antes não vivenciados, menos-valia pelo desprezo às suas queixas, medo do desconhecido diante das representações negativas da menopausa. Tornar inteligíveis as representações sociais de um dado grupo sobre o objeto menopausa implica analisar a eficácia dos discursos em relação às mudanças fisiológicas da mulher nessa etapa da vida, e iniciar um processo de troca entre população e profissionais no sentido de (re)construí-las a partir da crítica às representações dominantes que sustentam relações de poder, favorecendo a expressão dos sentimentos e emoções de maneira a possibilitar à mulher ser sujeito de sua saúde e ampliar o olhar e a sensibilidade dos profissionais da saúde. Palavras-chave Promoção da saúde, Representações sociais, Práticas educativas, Gênero, Menopausa 


\section{Introdução}

Climatério/ menopausa é sem dúvida, aqui no Brasil, uma temática que entra na agenda das discussões na década de 1990. Se havia um relativo silêncio a respeito, fosse pela escassa difusão de trabalhos científicos produzidos fora do Brasil, ou por ainda ser tema tabu entre as mulheres, o fato é que não deixava de ser uma questão relevante para as mesmas. No trabalho com grupos nos anos 80, no PAM 13 de Maio/RJ, dimensionávamos a grande demanda das mulheres na pré e pós-menopausa por uma atenção particularizada e que não era satisfeita nos limites da consulta ginecológica. Situando a menopausa em um processo global da vida da mulher, o texto de Pedrin et al. (1988), do Grupo de Mulheres de São Francisco, fora referência fundamental; a propósito, Gutiérrez (1992) cita que na América Latina não se tinha notícia de pesquisa semelhante sobre a menopausa. A experiência iniciada em 1988 com grupos de mulheres na meia-idade, descrita em "Mulher na menopausa: declínio ou renovação" (Gutiérrez, 1992) antecedera o projeto de atenção integral à saúde da mulher no climatério, implementado na referida unidade em meados de 1990, de cuja experiência nos valemos neste artigo.

No cenário internacional a realidade era outra. O ano de 1976 marcara a realização do I Congresso Internacional de Menopausa, definindo-se climatério - período de envelhecimento da mulher entre as fases produtiva e não produtiva; e menopausa - a data final das menstruações que ocorrem durante o climatério (Portinho, 1994). Também nesse ano, a International Menopause Society lança na França o periódico Maturitas, com a finalidade precípua de publicar os resultados de estudos e experiências complementares sobre reposição de hormônios, mas segundo Greer (1994) seu objetivo era e continua a ser conseguir subsídios do governo para divulgar o "evangelho" da terapia de reposição hormonal. A crítica incide sobre a ênfase na TRH em detrimento da valorização do processo natural da vida e de seu enfrentamento pelas próprias mulheres e/ou do exame de fatores que extrapolam o biológico.

Acompanhando os debates sobre essa temática, vemos que o aumento da esperança de vida da humanidade se transforma no principal argumento que justifica a maior difusão das pesquisas científicas, as matérias jornalísticas e programas de saúde.

Em 1993, o Ministério da Saúde incluiu no Programa de Assistência Integral à Saúde da
Mulher (PAISM) orientações específicas à assistência ao climatério, objetivando universalizar os procedimentos em diversos níveis de atendimento, contemplando a melhoria dos indicadores de saúde. Indica basicamente uma propedêutica médica, orientação dietética e orientação para programas de atividades físicas. Atividades educativas devem oferecer às clientes $o$ maior nível de atendimento sobre as modificações biológicas inerentes ao período do climatério, bem como propiciar adequada vigilância epidemiológica às situações de risco associadas. Os aspectos psicológicos e sexuais são, também, apontados como significativos nessa fase. Entendemos que cabe explorar não só esses aspectos, mas ampliar os debates sobre as práticas educativas e seus objetos, considerando que as usuárias necessitam de informações que lhes permitam ter um papel ativo diante das situações desconhecidas que as deixam inseguras e vulneráveis à medicalização.

\section{Climatério/menopausa: a importância das informações}

Uma revisão na literatura que discute a menopausa, destacando os primeiros cinco anos da década de 1990, permite sinalizar que o tema das mudanças por que passam as mulheres na meia-idade aparece como central, assim como se atribui importância à veiculação de informações. Contudo, a maneira como se interpreta a problemática da mulher engendra caminhos diversos e proposições diferenciadas, seja no próprio universo médico seja a partir do olhar diferenciado das feministas. Assim, situamos nossas discussões na perspectiva das respostas possíveis dos serviços públicos às demandas das mulheres que identificam problemas em relação à menopausa.

$\mathrm{Na}$ literatura médica, o termo climatério designa, basicamente, o ciclo da mulher caracterizado pelas mudanças hormonais (diminuição de estrogênio e progesterona), alterações vaginais e cessação da menstruação (menopausa). Reserva-se a expressão sindrome do climatério ao conjunto de sinais e sintomas que provocam mal-estar físico e emocional, resultante da insuficiência estrogênica, destacando-se, a curto prazo, ondas de calor, insônia, irritabilidade e depressão; a médio prazo: atrofia dos epitélios, mucosas e colágeno; a longo prazo: alterações cardiovasculares e perda de massa óssea (Luca, 1994). Há autores que classificam os sintomas em vasomotores (fogachos, suores, palpitações) psíquicos e 
somáticos. Como a menopausa ocorre dentro de um amplo período - climatério -, Bronstein (1994) considera que as modificações somáticas e psíquicas apresentadas pelas mulheres serão muito diferentes, assim como as alterações endócrinas, que merecerão considerações em separado conforme a fase em que se encontrem - período da maturidade feminina, perimenopausa ou início do envelhecimento.

Se o termo climatério era até então desconhecido da população usuária dos serviços de saúde, menopausa representava um marco das mudanças por que passa a mulher, não só em termos fisiológicos, mas aí acrescentando outros atributos, como por exemplo, na associação entre menopausa e início do envelhecimento e decadência, construções características de nossas sociedades e culturas ocidentais. Não que o discurso médico esteja desprovido desses atributos; na própria origem do termo, do grego Klimáter, temos o significado de "período crítico da vida”. Para Greer (1994) as pessoas só começaram a discutir o climatério depois de analisado e definido pelos médicos como uma síndrome: a classe médica adquiriu o poder de tratar a "fase crítica" (...) como um problema que exigia intervenção médica, e não como um importante processo inerente ao desenvolvimento feminino, que as próprias mulheres deviam enfrentar. Admite que este é um período difícil, sem exceção; um período de mudança e que é importante não se negar o evento em si e enfrentá-lo. As idéias de Greer desenvolvem-se tendo como diretriz um dos dogmas feministas - cabe à mulher definir sua própria experiência - e enfatiza: o trágico não é necessariamente esquecerse de si própria, mas a baixa auto-estima.

Enquanto a linguagem médica fala de sintomas e de processos fisiológicos, de reposição de hormônios, a das feministas fala da vida, do maior conhecimento de si própria, da utilização de produtos e técnicas naturais. Para Werthein et al. (1999) transformar os signos da menopausa em sintomas torna as mulheres mais vulneráveis à medicalização e habilita a pensar a menopausa como uma enfermidade e não como um fato vital. Pedrin et al. (1988) também sinalizavam uma tendência crescente na medicina para encarar a menopausa como uma fase de transição natural, mas que considerá-la uma doença de insuficiência era um aspecto ainda ensinado na maioria das escolas médicas.

A identificação de menopausa como doença é um mito, afirma o médico L. de Luca (1994) assim como considerá-la marco do envelheci- mento e da degradação física e mental. Admite, no entanto, que poucas mulheres estão isentas de sintomas e que para a maioria, menopausa significa o "inferno" do início do envelhecimento. O uso dessa metáfora sublinha a intensidade das sensações experimentadas por muitas, o que nos leva a indagar se para aquelas que vivenciam negativamente esse período é suficiente a definição do climatério como um processo natural e a afirmação de que não é uma doença. Como se explicam a existência de sintomas e a ênfase no tratamento para reposição de hormônios?

Aldrighi (1994) situa a "medicina climatérica" como uma importante parcela da medicina preventiva, o que permite às mulheres uma condição de vida mais digna no seu processo biológico natural de envelhecimento. Entre as muitas funções do médico inclui a de orientar as mulheres na pós-menopausa sobre o real significado da redução de hormônios e a necessidade de reposição hormonal - sempre avaliando a relação risco/benefício -, com o intuito de diminuir a incidência das afecções (...).

Salientando a importância do estudo da medicina climatérica, os médicos também reconhecem que há uma carência de informações adequadas à mulher.

Para Fonseca (1999) uma abordagem realista e tranqüilizadora e um bom relacionamento entre o médico e a paciente podem fazê-la aceitar a terapia de reposição com segurança. O argumento daqueles que defendem com veemência o uso de estrogênios depois da menopausa é baseado na intenção de se trabalhar na prevenção da osteoporose e das doenças cardiovasculares. Sabemos que o risco de o uso de estrogênios aumentar os casos de câncer do corpo uterino é desprezivel, desde que a paciente submetida à terapia de reposição seja mantida sob rigorosa atenção médica.

A questão dos esclarecimentos risco/benefícios na terapia de reposição hormonal (TRH), bem como a atitude do médico como fonte de informação vêm enfatizadas por L. de Luca (1994): no que se refere à terapêutica de reposição no climatério é preciso adotar postura franca e simpática. É dever profissional esclarecer a função dos hormônios, quais são eles, por que ministrá-los, quando iniciar o tratamento e qual a sua duração. Informar sobre os efeitos colaterais, desde os mais simples aos mais graves. Discutir os esquemas de medicação e esclarecer as dúvidas pertinentes e cabíveis, impertinentes e descabidas. Atitudes médicas negativas, autoritárias, às vezes zombeteiras, são contraproducentes e respondem, não raro, pelo nascimento de mitos ou de meias-verdades. 
Se é dever ético profissional prestar esclarecimentos em relação à TRH, considerando-se os direitos do paciente, há, no entanto, limites em termos da prática médica nos espaços dos serviços públicos de saúde. Dentre outros, o pequeno tempo de que se dispõe para elaborar informações com as usuárias, levando-se em conta que se faz necessário uma aproximação com o universo sociocultural da população usuária. Em nossa experiência encontramos usuárias, que vindas de outras unidades, haviam feito TRH e/ ou interrompido o tratamento, desconhecendo o teor do mesmo. Também já ouvimos depoimento de médicos, que convencidos da eficácia do TRH o prescrevem ainda que não tenham possibilidade de tecer ampla informação à "paciente"; há ainda os que não admitem contra-argumentação. Nesse sentido cabe a observação, acima citada, de Luca, que não descarta a existência do discurso autoritário. Cabe ressaltar não se tratar de um exagero a referência a atitudes zombeteiras, quando as flagramos atreladas às representações da mulher poliqueixosa, da que não tem parceiro, da mulher velha, da ignorante, e etc.

$O$ fato é que embora se reconheça que a TRH não seja a única medida no climatério, sendo suas coadjuvantes uma alimentação correta, exercícios físicos adequados e orientação psicológica, a discussão na medicina se centra na TRH: Muitas vezes a depressão, as ondas de calor, o nervosismo e a tristeza observadas podem ser de origem emocional, e mesmo na ausência de menstruação, não é fácil detectar muita coisa além das alterações dos níveis hormonais ou as condições que possam justificar toda esta sintomatologia. O arsenal terapêutico disponível atualmente pode aliviar com sucesso os distúrbios do climatério e facilitar muito o tratamento (Fonseca, 1999).

Por outro lado, fora da especialidade climatério, muitas vezes ignoram as queixas das mulheres, entendendo que nada há a fazer: Comecei a sentir coisas diferentes, embora menstruando normalmente (...) O médico disse: "O melhor é esquecer"; só que todas as vezes que estava pra menstruar, ficava naquela indisposição..., meu rosto ficava inchado; pensava, "estou tendo perda de alguma coisa". Não sei se tem uma reposição hormonal; é só depois que a menstruação vai embora? (Fala numa reunião de sala-de-espera).

$\mathrm{O}$ acesso à saúde, nos lembra Rosenberg (1992), é estruturado em torno do que foi construído como legítimo na avaliação diagnóstica, assim como as terapêuticas. Se as causas para os "sintomas" no climatério podem ser agrupadas em três grandes categorias - redução dos estrógenos, fatores socioculturais e fatores de personalidade -, para Stepke (1997), o "peso etiológico" de cada causa difere, (...) só à primeira, em geral, se atribui a possibilidade de estabelecer procedimentos adequados para explicitá-lo e deduzir dessa explicitação medidas cientificamente fundamentadas (...). No entanto, estudos epidemiológicos evidenciam que as mulheres que têm acesso às informações passam mais tranqüilamente o climatério e, há, ainda, evidências de diversos antecedentes para essa sintomatologia: a saúde prévia, emocional e física; as expectativas em relação à própria vida; a valorização da maternidade em determinadas culturas; a ausência de menstruação, valorada de forma positiva ou negativa. Inferimos ser este um processo natural que é vivido em condições diferenciadas, dependendo de vários fatores, desde os genéticos e do meioambiente aos que estão ligados às condições de vida e de trabalho.

Embora não pretendamos discutir riscos e benefícios da TRH, sinalizamos que, contrapondo-se à já inquestionável adesão de muitos médicos à referida terapia, a Rede Nacional Feminista de Saúde e Direitos Reprodutivos, preparou um dossiê (2001) em que a crítica à medicalização da menopausa é acompanhada de dados que corroboram a idéia de que os estudos sobre hormônios de reposição ainda são contraditórios e também em Greer (1994) encontramos referências a pesquisas que se contradizem.

Considerando que as informações necessárias à população usuária dos serviços públicos vão além das informações em termos da reposição de hormônios, esclarecimentos sobre os mecanismos fisiológicos e a própria anatomia, reconhecemos os limites da medicina para dar conta dos diversos fatores imbricados na problemática da mulher no climatério. Deve-se admitir que não é apenas com uma conversa franca que se soluciona as imensas dúvidas das mulheres ou se desconstrói a idéia que se faz da mulher madura ainda diretamente ligada à velhice que a exclui da vida ativa. Envelhecer também depende do gênero, sendo distintas as cronologias femininas e masculinas. Por outro lado a idéia de mudanças no estilo de vida vão ter de ser trabalhadas, levando-se em conta as condições de vida e os valores em relação à alimentação, ao tempo disponível para os cuidados de si, as representações do corpo e do tempo socialmente úteis, entre outros. 
Consideramos ainda que o evento biológico que marca a menopausa vem acompanhado de inúmeras imagens e metáforas que nos indicam um caminho para estudar as representações sociais às quais estão ligadas. Cabe desvendar as construções em relação aos grupos de idade, de gênero, do tempo e do corpo a elas associadas e tomá-las como matéria-prima para trabalhar as informações nas práticas educativas.

\section{Representações de gênero}

Como modo de conhecimento prático, compartilhado, orientado para a compreensão do mundo e para a comunicação, as representações sociais (RS) - diante dos inúmeros objetos, pessoas, acontecimentos ou idéias - nos guiam no modo de nomear e definir conjuntamente os diferentes aspectos da realidade diária, no modo de interpretar esses aspectos, tomar decisões e, eventualmente, posicionarmo-nos frente a eles de forma defensiva (Jodelet, 2001).

Referenciamo-nos, também, em Bourdieu (1996) que ao enfocar a dominação masculina considera que ela está suficientemente assegurada nas sociedades ocidentais, exprimindo-se sob forma de evidências, nos discursos (ditados, provérbios, etc.), nos objetos técnicos, nas práticas. Existe nas coisas, sob forma de divisões espaciais entre os espaços femininos e masculinos e sob a forma de instrumentos diferenciados, masculinos ou femininos que são "as estruturas inscritas na objetividade", o que significa que estão inscritas, nos corpos sob a forma de disposições corporais visíveis na maneira de usar o corpo. Existe, também, nas mentes, sob forma de princípios de visão e de divisão, de taxionomias, de princípios de classificação que estão inscritas na subjetividade, sob forma de princípios de percepção dos corpos dos outros.

Ao tomarmos as RS da menopausa temos exemplos de como se entrelaçam o pensamento popular, o ideológico e o científico. Alguns dos subtítulos de livros de autores que citamos nos remetem às funções cognitivas no processo de RS. Ao pretenderem ser atraentes ao público feminino e difundir a idéia de reposição hormonal, alguns vão buscar aqueles conteúdos mais estáveis nas culturas e sociedades ocidentais, dentre os quais estão as construções que naturalizam as ações e comportamentos, calcados em justificativas que se apóiam em explicações biologicistas, que no senso comum se traduzem em expressões do tipo: "faz parte da natureza feminina". Num dos subtítulos, "O eclipse da lua”, a imagem que faz associar a mulher à natureza, obscurece o sentido que o próprio livro pretende que é dar visibilidade e voz às mulheres no mundo da cultura. Por que, "Para sempre mulher”?, outro subtítulo escolhido, ou por que, ainda, "Feminina para sempre”?, expressão não só utilizada em fôlderes de propagandas de laboratórios, mas reafirmada em fóruns médicos. Não nos remetem eles à idéia da fusão entre sangue menstrual, fertilidade e feminilidade? Não estaria aí vinculada a idéia de ser mulher com a aptidão de ser feminina, de ser sexualmente desejável e atraente, arquétipos equivalentes à juventude? O texto de Werthein et al. (1999) nos sugere ainda a questão: Não se estaria confirmando a associação entre sangramento menstrual e juventude, sangue e vitalidade, que marca os limites de entrada e saída do mercado erótico/sexual?

Destacamos a partir dos subtítulos acima mencionados, algumas condições que afetam os aspectos cognitivos, ao nível da emergência das representações, a saber - o foco sobre certos aspectos do objeto, em função dos interesses e da implicação dos sujeitos, a pressão à inferência, no sentido de se obter a adesão do público feminino. Nesse sentido, como vetor de transmissão da linguagem, a comunicação contribui para forjar representações que são pertinentes para a vida prática e afetiva dos grupos (Jodelet, 2001).

A imagem do ser feminina, construída a partir de valores sedimentados na beleza, na juventude, na fertilidade, atinge profundamente a identidade da mulher. Nesse sentido, a menopausa representada como momento crítico afeta negativamente a construção da sua autoimagem. Para Werthein et al. (1999) antes mesmo que as mudanças corporais venham produzir impactos psicológicos, são os discursos vigentes, o imaginário social, que denigrem e desvalorizam nosso corpo, que segregam nossos desejos.

\section{Práticas e representações sociais}

Situamo-nos no início dos anos 90 no contexto de uma unidade médico-assistencial, referenciada na introdução do artigo, onde atuamos como assistente social na atenção à mulher no climatério (1990/1995) juntamente com médicos - ginecologista e clínico -, psicólogo, nutricionista, enfermeira e fisioterapeuta.

Quebrando o silêncio em torno da menopausa, estimulando a expressão de sentimentos 
e vivências, os debates de toda a equipe com a população, em reuniões quinzenais, por vezes reuniam cerca de cem usuárias. Na rotina dos atendimentos, os grupos de sala-de-espera, com duração média de sessenta a noventa minutos, eram em geral conduzidos por uma assistente social, com a participação de outro membro da equipe, pretendendo ser um dispositivo para a participação ativa das usuárias no processo saúde/doença. Na condução dos grupos distinguimos dentre os eixos temáticos: romper o silêncio, questionando as representações em torno dos saberes e das práticas de saúde; contextualizando os serviços de saúde e as politicas de saúde; socializar informações, tendo como conteúdo o corpo, as modificações biológicas, os fatores socioculturais e psicológicos; a prevenção de doenças e sua relação com diferentes estilos de vida; a reposição hormonal (vantagens e desvantagens); - as diferentes condutas terapêuticas

Registramos das reuniões o que seria a indagação central, a postura inicial das usuárias, diante da necessidade de entenderem as mudanças por que estavam passando ou pelas quais poderiam passar: O que está de fato acontecendo comigo? Ou, o que poderá vir a acontecer comigo?

À medida que iam obtendo informações, teciam críticas à ausência das mesmas no âmbito dos serviços públicos de saúde e de não serem ouvidas: "Os médicos cumprem suas obrigações, mas não revelam a necessidade de uma orientação sobre o climatério"; "faltam informações, pois os médicos não explicam, atribuem tudo à idade", ou "a pouca informação sobre a menopausa se reflete na maneira como as pessoas reagem às queixas das mulheres". Nessas falas estão dizendo que ao não ser dada a devida atenção às suas queixas os problemas deixam de ser discriminados, negligenciando-se possíveis medidas na prevenção de doenças ou promoção da saúde, bem como ao se atribuir tudo à idade se generaliza, o que resulta na combinação mulher poliqueixosa / mulher velha.

\section{Perfil da população usuária}

Em 1994 com o objetivo de precisar o perfil da população usuária e levantar os fatores socioculturais na problemática da mulher no climatério-menopausa, realizamos 289 entrevistas semi-estruturadas no próprio setor do climatério entre os meses de agosto a dezembro, correspondendo aproximadamente a $35 \%$ do total de atendimentos realizados no período. Nesse universo, 144 ainda não haviam passado por nenhum atendimento na referida clínica (usuárias iniciais) e as 145 restantes já estavam em atendimento (subseqüentes). Duas perguntas abertas - o que sabiam sobre climatério-menopausa; e como se sentiam na atual fase da vida - nos levaram a novo exame dos dados dessa pesquisa, por ocasião do nosso projeto de tese, em que tomamos como objeto de estudo as representações sociais como matéria-prima das práticas educativas. Ao indagarmos sobre a relação entre representações e as vivências da menopausa, acrescentamos aos dados do perfil alguns significados que emergiram com a análise temática. Consideramos que as visões compartilhadas das mudanças na menopausa vêm ancoradas não apenas nas construções médicas via linguagem dos sintomas, mas que as construções ideológicas de gênero "transversalizam" as representações e as práticas, o que se torna mais evidente quando os temas remetem ao envelhecimento, à sexualidade, às diferentes atitudes femininas $\mathrm{e}$ masculinas diante desses processos.

\section{Características socioeconômicas}

A população usuária majoritariamente encontrava-se na faixa etária de 45 a 49 anos (31,5\%) e 45 a 54 anos $(28,1 \%)$, perfazendo um total de $59,9 \%$.

Considerando-se os anos da pré e pós-menopausa e as dificuldades para se arbitrar o momento de inclusão da mulher nos serviços do climatério, prevalecia no momento que realizamos a pesquisa o critério mais elástico dos 40 aos 60 anos, conforme podemos observar na tabela 1 .

Nesse universo, 232 mulheres (80,3\%) tiveram filhos e $216(74,07 \%)$ declararam ter companheiros. Em 65,8\% dos casos a renda familiar era inferior a cinco salários mínimos Na situação de casais, em apenas $2 \%$ dos casos a contribuição principal era da mulher.

Quanto ao grau de escolaridade, a maioria das mulheres não concluíra o primeiro grau $(63,7 \%)$, enquanto que no universo masculino esse percentual era menor (44\%).

Em relação ao trabalho, na categoria "doméstico" estavam $57,8 \%$, sendo que $10,7 \%$ exerciam algum trabalho remunerado e $9 \%$ estavam aposentadas. Na categoria "extradoméstico" foram incluídas as que declararam o trabalho remunerado como principal $(40,5 \%)$, sendo o 
mesmo exercido no domicílio por $8,3 \%$ ( $1 \%$ estando aposentadas) e no mercado formal ou informal por 32,2\% (1,4\% estando aposentadas). Não responderam, 1,7\%. Quanto ao grau de satisfação com o trabalho, 55\% apontavam a natureza do trabalho que exerciam como o principal motivo para estarem apenas parcialmente satisfeitas ou insatisfeitas.Apenas $1 / 3$ contribuía para a previdência social. Entre as que exerciam trabalho remunerado, em $97,2 \%$ das situações as atividades estavam ligadas ao ramo de serviços que se ajustam às qualidades femininas e baixa remuneração.

Não encontramos correlação significativa entre as variáveis trabalhar no lar ou fora do lar e grau de satisfação, tendo naquela ocasião submetido as variáveis a testes estatísticos (QuiQuadrado, correlações derivadas e Kramer; teste de hipóteses), assim como entre as variáveis faixas de idade, composição do grupo de convívio, renda familiar, religião - e as vivências da menopausa qualificadas como positivas ou negativas; já entre nível de escolaridade e expectativas na nomeação do que esperavam do atendimento no climatério encontramos diferenças, conteúdos que iremos explorar a seguir.

\section{O acesso aos serviços do climatério}

A população usuária procedia de diversos bairros do Rio de Janeiro e de alguns municípios de sua região metropolitana. A fonte de informação era diversificada, conforme o quadro 1.

Para os profissionais da saúde foram promovidos dois simpósios sobre climatério (11/6/ 1991 e 27/11/1992) por iniciativa do médico responsável pelo serviço do climatério, com a participação de toda equipe.

Nesse universo, apenas 100 mulheres foram encaminhadas por médicos; dentre elas 68 afirmaram não terem sido esclarecidas sobre o motivo do encaminhamento; as demais, apenas parcialmente esclarecidas. Este fato corrobora o que afirmávamos sobre as barreiras na comunicação entre médico e usuárias dos serviços públicos. Majoritariamente foram as próprias mulheres que identificaram problemas que associavam à menopausa, dentre as 189 usuárias que procuraram por !iniciativa própria!, sendo a referência principal as informações do tipo boca a boca (quadro 1).

Há relação entre a demanda por tratamento e as representações dos sintomas por elas percebidos?
Tabela 1

Proporção das mulheres por faixa etária.

\begin{tabular}{lrr}
\hline Faixa etária & n & \% \\
\hline menos de 40 anos & 8 & 2,7 \\
40 a 44 anos & 43 & 14,9 \\
45 a 49 anos & 91 & 31,5 \\
50 a 54 anos & 82 & 28,4 \\
55 a 60 anos & 48 & 16,6 \\
mais de 60 anos & 17 & 5,9 \\
Total & $\mathbf{2 8 9}$ & $\mathbf{1 0 0 , 0}$ \\
\hline
\end{tabular}

Fonte: Relatório de pesquisa. Prodir II, Fundação Carlos Chagas,1996.

Nas entrevistas duas perguntas abertas permitiram inferir que há um elenco de sintomas para representarem a menopausa. Respondendo o que sabiam sobre climatério-menopausa, apenas 8 entrevistadas não falaram dos sinais da menopausa, correspondendo na linguagem médica aos sintomas do climatério; sobre como se sentiam na atual fase da vida, só 23 não remeteram à mesma linguagem dos sintomas.

As respostas foram ordenadas segundo a classificação de Payer (1991 apud Portinho, 1994), que subdivide os sintomas climatéricos em vasomotores (fogachos, suores, palpitações); psicológicos (nervosismo, ansiedade, irritabilidade, cefaléia, depressão, insônia); somáticos (dispareunia, dor articular, esquecimento, fadiga, disúria, ressecamento da pele). Conforme a figura 1, "sobre o que sabiam" predominaram os sintomas vasomotores, considerados típicos da menopausa (N158), seguindo-se os psicológicos, considerados atípicos, porque podem ocorrer em qualquer momento da vida (N117) e somáticos (N21). Já quanto às vivências os sintomas psicológicos (N145) vão predominar sobre os vasomotores (N67) e aumentam as queixas somáticas (N58).

Admitindo-se respostas múltiplas, disseram ainda a respeito da menopausa: é o fim da menstruação (N60); falta de hormônios (N35); é necessário tratamento (N22); não é doença (N9). As expressões "nada sei ou sei muito pouco" (N53), significando que não tiveram acesso ou as informações de que necessitavam não eram suficientes e "o que sei é o que sinto" (N19), cujo único parâmetro é o que seu próprio corpo revela, foram referenciadas em sua maioria pelas usuárias iniciais entrevistadas. Destacamos, ainda, a idéia de que "a mulher que não se trata pode ficar louca", "pode subir pra cabeça", "há risco de morte". Em torno da menstruação a representação de "alívio", "purificação". 
Quadro 1

A fonte de informação.

\begin{tabular}{lc}
\hline Fonte & No \\
\hline Comunicações diversas (vizinhas, amigas, parentes, fila de marcação & 118 \\
de consulta, cartazes afixados no PAM) & \\
Setor de ginecologia do PAM & 85 \\
Serviços diversos do PAM & 38 \\
Outras unidades de saúde & 28 \\
Mídia & 20 \\
Total & $\mathbf{2 8 9}$
\end{tabular}

Fonte: Relatório de pesquisa. Prodir II, Fundação Carlos Chagas, 1996.

\section{Figura 1}

Representações da menopausa.

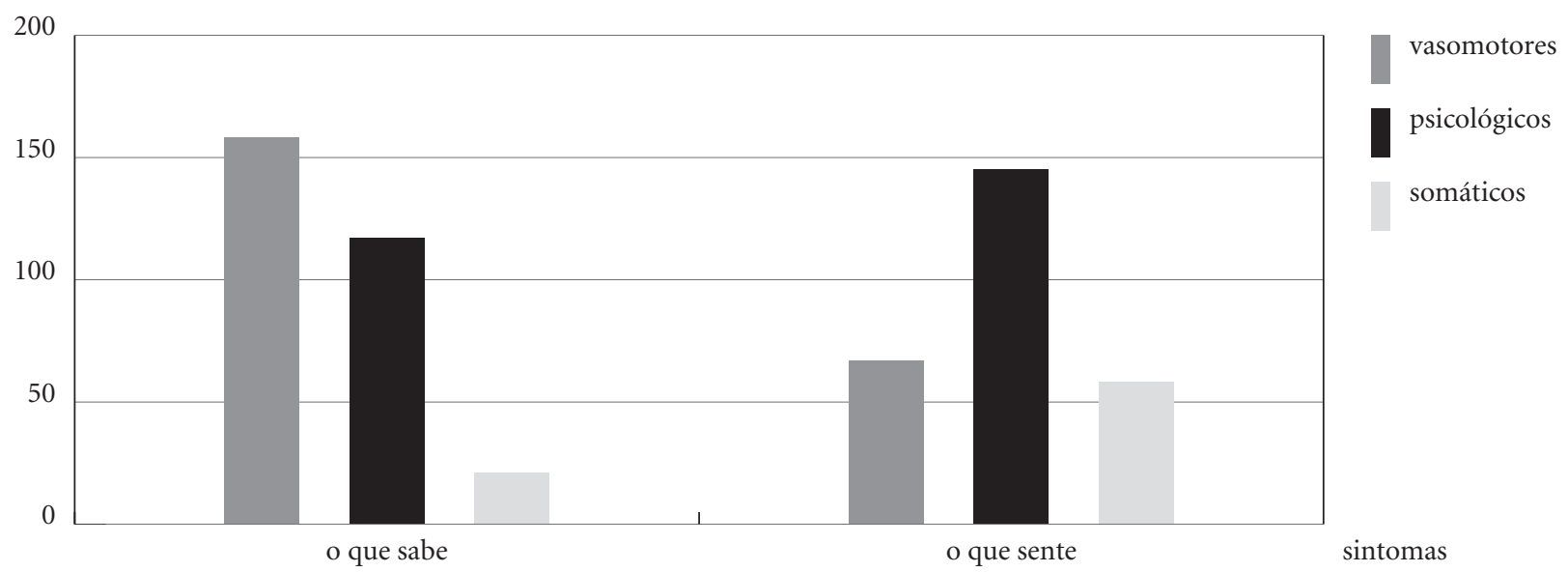

Se era no corpo que ancoravam as mudanças que estavam percebendo em si, é no sistema médico que vão buscar o reconhecimento e a legitimidade da definição de sua situação. Para a maioria a expectativa era de melhorar (N89), receber tratamento adequado (N58) ou fazer todos os exames (N20). Prevenir problemas e/ou doenças, receber informação e orientação foram as expectativas de 65 mulheres. Referiramse de forma mais ampla, a ter bom atendimento (N31). Já a representação de cura que supõe o entendimento de menopausa como doença aparecia em 44 respostas, majoritariamente entre as de baixa escolaridade e que estavam tendo um primeiro contato no serviço. Algumas delas assim se expressaram: "Espero que me traga uma solução para o problema da menopausa, que não me deixe neurótica"; "que o médico me livre do problema da menopausa, me livre da enfermidade; que fique bem, obedecendo às ordens médicas"; "Sei que não é doença, porque vi no jornal, mas mesmo assim estou vendo como doença, porque sinto calor, dor de cabeça, pressão alta, nervosa, desanimada, sem coragem para fazer nada”.

Por outro lado, encontramos várias falas em que as mulheres afirmam que estão bem, mesmo com a presença de sintomas. Ao reexaminar os dados dessa pesquisa, nos detivemos em 163 entrevistas, em que não só apontaram sintomas, como qualificaram a sua fase da vida. expressando sentirem-se bem ou normal (N83); 
nada sentirem (N 23); sentirem-se mal (diferente, fora do normal, mal, muito mal ou péssima)(N 57).

Ao lembrarmos que o pensamento médico oscila entre duas representações, a ontológica e a vitalista -, a representação de doença não passa apenas pela localização de um órgão doente. Para Canguilhem (1978), o homem é são na medida em que é normativo em relação às flutuações de seu meio e o médico geralmente tira a norma de seu conhecimento da fisiologia, dita ciência do homem normal, de sua experiência vivida das funções orgânicas e da representação comum da norma num meio social em dado momento. Se o conceito de doença conserva uma relação com o conceito axiológico de doença, para Canguilhem voltar a ser normal significa retornar a uma atividade interrompida ou pelo menos uma atividade considerada equivalente, segundo os gostos individuais ou os valores sociais do meio; citando Japers, afirma: é a apreciação dos pacientes e das idéias dominantes do meio social que determina o que chamar "doença". Procuramos explorar os significados em torno das expressões utilizadas pelas usuárias.

\section{Vivências da menopausa}

Dentre as que afirmaram sentir-se bem, 23 utilizam o termo normal, apesar de apontarem os "calores" e problemas somáticos. Vamos observar que as expressões "estar bem”, "estar normal" ou "não sentir nada de anormal", "levar a vida normal" têm equivalência, quando se relacionam com as expectativas de mudanças com a chegada da menopausa, mudanças valoradas como negativas. Há sempre uma expectativa de mudança. Entre as que "nada sentem" (N23), o fator idade é mencionado pela maioria como razão para o atendimento na prevenção de problemas, sendo que estar normal ou viver normalmente também aparece em quatro respostas. Podemos dizer que as alterações fisiológicas são minimizadas, encaradas como naturais no ciclo de vida da mulher e que seriam os sintomas psicológicos os responsáveis pelas mudanças negativas esperadas. Os fatores psicológicos interviriam no auto-controle, seriam responsáveis pela mudança de comportamento e afetariam as relações sociais. Entre as que se sentem bem, encontramos somente duas respostas que apontam para os sintomas psicológicos: Continuo com a vida normal, apesar de angustiada, com insônia e estou me sentindo bem, embora te- nha depressão; acho que isso faz parte do dia-adia. Já entre as que se sentem mal, vão predominar os sintomas psicológicos. Identificamos dentre as 83 respostas, três elementos cujos conteúdos permitem caracterizar a relação entre os termos - bem ou normal - e mudança: afirmação de si, aceitação, positividade/estar ativa, elementos estes ligados à representação que o sujeito faz de si, ou seja, de sua identidade. Nesses depoimentos há uma negação de problemas, uma vez que os transtornos físicos não afetaram as relações sociais e a identidade, o que poderia ocorrer quanto aos transtornos psicológicos. Ilustramos com algumas falas: "Apesar dos sintomas, não senti mudanças; continuo a mesma; tem que aceitar essa fase"; "não alterou nada; sou uma pessoa calma, tranqüila” ou "o relacionamento conjugal e familiar não mudou nada". Em todas as demais falas significaram que foram preparadas ou mesmo educadas para encararem os diferentes ciclos da vida da mulher, enfatizando que se os sintomas que sentem são próprios dessa fase; cabe encará-los e minimizar seus efeitos; também o auto-controle está aí valorizado e a aceitação do envelhecimento. Distinguimos, também, aquelas que enfatizam a temporalidade do fenômeno: $\mathrm{Me}$ sinto normal, mas tenho reações inesperadas iguais à adolescência, depois passa. Encontramos a positividade (valorização, avaliação, estima): a) por estarem informadas - "consciente da mudança do corpo e da cabeça, tentando diminuir sintomas e ser mais feliz", por estar "livre da menstruação", "sem perigo de gravidez" ou" posso trabalhar sem preocupação da menstruação vir"; b) estar ativa: "apesar do calor, estou me sentindo bem, trabalho, ando, passeio; disposição eu tenho".

$\mathrm{Na}$ categoria das que se sentem mal predominam sintomas psicológicos, havendo uma qualificação negativa dessa fase da vida, associados em grande parte à depressão: Fase muito ruim, a gente fica sem paciência, dá vontade de chorar, não dorme direito. Grande parte referese a não ter vontade de fazer nada, significando perder o gosto pela vida ou viver por viver: Estou me sentindo apática; sem vontade de fazer as coisas ..., de me cuidar, de ter relação sexual; sem interesse pela vida. Referem-se ainda à falta de paciência consigo próprias e com os outros: "Tomo calmante pra me agüentar", "não tenho nem paciência comigo; choro muito; tenho vontade de morrer". Encontramos também respostas em que generalizavam, remetendo à idéia de envelhecimento e de morte: "É horrível, a idade 
vai chegando, às vezes pensa que já está no fim, que a vida tá acabando; muita tensão", "sinto desgosto, acho que é depressão; só não tenho vontade de morrer porque tenho medo", "choro sem motivo; não sei se isso é alguma doença ou se évelhice". Além da indisposição para atos de rotina e da indisposição para o trabalho, referentes apontados, encontramos uma resposta que remete ao fim do período fértil: "Sinto-me sem vigor, pois perdi a capacidade de procriar, mas tenho que ultrapassar essa fase, pois tenho marido e filhos para cuidar".

A associação entre menopausa e o fato de estarem frias sexualmente, desinteressadas, ou sem desejo foi citada por nove das entrevistadas subseqüentes entre as que sentem-se mal, sendo que apenas duas fizeram referência à " ressecamento vaginal".

Considerando o universo da pesquisa (N289), encontramos em 50 entrevistas referências à sexualidade, sendo que 34 estavam entre as usuárias subseqüentes. Cabe observar que eram sobretudo as discussões dos grupos de sala-de-espera que ensejavam a aproximação com a temática, a partir de algumas representações que eram discutidas. Encontramos como referentes além dos elementos citados, dúvidas se o desinteresse sexual era "do hormônio ou de cabeça" ou por "problemas familiares". A referência ao aumento do prazer sexual foi feita por três entrevistadas iniciais e duas subseqüentes.

Se nas entrevistas nos falam das mudanças esperadas e de suas vivências, dos cuidados com a saúde, das relações sociais no âmbito da família e do trabalho, da sexualidade, envelhecimento e de sua identidade, é nos grupos de reflexão que vão poder problematizar esses vários aspectos: Em casa e no trabalho as mulheres passam a serem vistas como velhas, com mania de doença e acaba sendo descartável; a mulher fica mais irritadiça; mais difícil de conviver no trabalho; os homens não entendem o que acontece com as mulheres; os homens passam por dificuldades, mas em geral ocultam e buscam outras saidas; mudam de vida, mudam de mulher. Temos pois que, os sinais da menopausa são visíveis e, como tais, sejam eles fogachos, suores, irritabilidade, fadiga, indisposição para o trabalho, e mesmo a depressão, entre outros, marcam um dos significados da menopausa, o da mulher poliqueixosa, representação que, também, não se faz ausente entre profissionais no setor saúde. Contudo, associado à idéia da mulher poliqueixosa, encontramos um outro significado, em que as queixas somáticas e/ou psicológicas são sinais que se transformam em signos do envelhecimento e estes trazem a marca de gênero. Estamos, portanto, nos referindo aos símbolos da menopausa, dos sentidos produzidos fora do objeto e que, exercem uma eficácia prática, sendo um referencial que pode ser evocado em diversas circunstâncias.

Para os homens não há uma representação em torno da andropausa e, assim, para o homem de meia-idade, não há um rito de passagem. O envelhecimento sendo vivido como natural, prolonga-se o seu enquadramento na categoria de velho. Enquanto a mulher na menopausa pode ser taxada de velha, como expressam por vezes as usuárias, os homens na faixa etária correspondente são maduros, trazendo outros predicados que não interferem negativamente, podendo até contribuir para sua maior auto-estima diante da experiência de vida. Também nas reuniões falavam da necessidade de espaço para exercerem sua subjetividade ou consideravam a menopausa, como momento de reafirmação, como de defesa do espaço conquistado, de tudo que se fez, não se admitindo cobranças. Falam dos homens virem às palestras, das dificuldade em acompanharem suas mulheres nesse processo e, também de verem o corpo envelhecer e procurarem ajuda, quando necessário.

Assim, consideramos mais dois eixos temáticos na condução dos grupos: a) particularizar a situação da mulher na sociedade brasileira, visando relativizar as vivências singulares no confronto de experiências, considerando condições de vida, de trabalho e fatores opressores da mulher, avaliando os limites em relação aos seguintes aspectos - o público e privado, o usufruto dos bens e serviços, o acesso a informações, os valores de nossa sociedade ocidental; b) revalorizar a mulher, visando maior autoconhecimento e maior autoestima, avaliando: perdas e ganhos, possibilidades e limites da mulher nessa etapa da vida (Mendonça, 1996).

\section{Considerações finais}

Quando o trabalho em equipe multidisciplinar se faz necessário, tendo em vista uma maior eficácia na intervenção nos níveis das ações preventivas e de promoção da saúde é necessário construir o processo de trabalho coletivo. A não-inclusão do auto-conhecimento como objeto de preocupação da epistemologia objetivista, certamente ajudou a manter uma fronteira nítida entre a vida cotidiana e a ciência, e entre a 
ciência e a política, e a desqualificação da produção de conhecimento no cotidiano (Giffin et al., 2000). Também as emoções, na tradição filosófica ocidental, têm sido consideradas potencial ou realmente prejudiciais ao conhecimento (Jaggar, 1997) e, enquanto a razão vem associada ao mental, ao cultural, ao universal, ao público e ao masculino, a emoção é associada ao irracional, ao físico, ao natural, ao particular, ao privado e, obviamente ao feminino.

Se o objetivo último da promoção da saúde é o fortalecimento da mulher como sujeito da saúde, isto implica deixar de ser paciente, quando outros falam por nós para reivindicar informações, direitos, destinar tempo para si, ao auto-cuidado, ter prazer em suas atividades, entre outras possíveis descobertas. Do momento que encontram um espaço para falar, ouvir e trocar, há uma maior compreensão do processo que estão vivendo, sendo necessário que se elabore as informações a partir de sua realidade. Como interpretar - eu queria voltar a ser como antes!, ignorando-se o lugar de onde fala a mulher, o seu capital cultural, as suas relações sociais, a sua linguagem dos interditos, o que é para ela normal. A linguagem das nossas usuárias está em grande parte marcada pela significação do outro, em que muitas das idéias que circulam sustentam relações de poder e dominação. Embora as vivências não sejam as mesmas, há uma expectativa de declínio, renovação, entre outras. Se abrimos espaços para intersubjetividade no processo de conhecimento, para a interação e a troca, vamos nos guiar em termos de compartilharmos conhecimentos com as usuárias dos serviços de saúde no desenvolvimento das práticas educativas e despirmos a palavra da autoridade institucional que inibe o interlocutor.

Considerando a menopausa novo objeto na saúde no início dos anos 90, e que silenciado, gerava o discurso "tudo é por conta da menopausa", indagamos, diante da complexidade da abordagem da promoção da saúde, que conteúdos persistem e por que e quais os passíveis de transformações no processo de interação entre os sujeitos. 


\section{Referências bibliográficas}

Aldrighi JM (org.) 1994. Climatério-especial. Ars Curandi, A Revista da Clínica Médica 8(27): 13.

Bourdieu P 1996. Novas reflexões sobre a dominação masculina, pp. 28-40. In M Lopes, D Meyer \& V Valdow (orgs.). Gênero e saúde. Artes Médicas, Porto Alegre.

Bronstein MD 1994. Climatério: o papel do endocrinologista. Ars curandi, A Revista da Clínica Médica 8(27): 85-90.

Canguilhem G 1978. O normal e o patológico. Ed. ForenseUniversitária, Rio de Janeiro.

Fonseca PT 1999. Menopausa: para sempre mulher. Ed. Vozes, Petrópolis.

Giffin et al. 2000. Homens, saúde e vida cotidiana: uma proposta de pesquisa/ação. VI Congresso Brasileiro de saúde Coletiva, Salvador.

Godin A, Coslovsky S \& Martins V 1994. Eclipse da lua: um dossiê sobre a menopausa. Relume-Dumará, Rio de Janeiro.

Greer G 1994. Mulher: maturidade e mudança. Ed. Augustus, São Paulo.

Gutiérrez E (org.) 1992. Mulher na menopausa: declínio ou renovação? Rosa dos Tempos, Rio de Janeiro.

Jaggar AM 1997. Amor e conhecimento: a emoção na epistemologia feminista, pp. 157-185. In AM Jaggar \& SR Bordo (eds.). Gênero, corpo e conhecimento. RecordRosa dos Tempos, Rio de Janeiro.

Jodelet D 2001. Representações sociais: um domínio em expansão, pp. 17-44. In D Jodelet (org.). As representações sociais. EdUERJ, Rio de Janeiro.

Lopes GP 1994. Sexualidade. Ars Curandi, A Revista da Clínica Médica 8(27): 80-84.

Luca LA 1994. Climatério: mitos e verdades. Ars Curandi, A Revista da Clínica Médica 8(27):17-26.

Mendonça EAP 1997. Ciclo de vida e os mitos da menopausa, pp. 49-66. In DP Marques (org.). Saúde, sexualidade e reprodução: compartilhando responsabilidades. UERJ/FSS, Rio de Janeiro.

Mendonça EAP 1996. A atenção integral à saúde da mulher no climatério. Em Pauta, Caderno da Faculdade de Serviço Social da UERJ 7: 71-90.
Mendonça EAP 1996. Relatório de pesquisa: A influência dos padrões socioculturais na problemática da mulher no climatério-menopausa. Fundação Carlos Chagas, Programa de Treinamento em Pesquisa sobre Direitos Reprodutivos na América Latina e Caribe -PRODIR II, São Paulo.

Ministério da saúde. Secretaria de Assistência à Saúde. Departamento de Programas de Saúde. Coordenação Materno-Infantil. Serviço de Assistência à Saúde da Mulher 1993. Assistência ao climatério. Brasília: COSMI.

Pedrin V, Beverly R \& Karla W 1988. Menopausa: um processo natural, apêndice, pp. 35-40. In E Gutiérrez (org.). Mulher na menopausa: declínio ou renovação? Rosa dos Tempos, Rio de Janeiro.

Payer L 1991. Menopause in various cultures, pp. 122-128. In $\mathrm{H}$ Burger \& M Boulet. A portrait of the menopause. The Participation Publishing Group, Nova Jersey.

Portinho JA 1994. Correlação de fatores sócio-demográficos e sintomas. Dissertação de mestrado, Instituto de Ginecologia da Universidade Federal do Rio de Janeiro, $119 \mathrm{pp}$.

Rede Nacional Feminista de Saúde e Direitos Reprodutivos 2001. Dossiê: Menopausa não é doença, é mais uma fase na vida. Disponível em <http://www.redesaude. org.br>

Rosenberg CE 1992. Framing disease: illness, society and history, Introduction pp. xiii-xxvi. In C Rosenberg \& J Golden (org.). Studies in cultural history, health and medecine in American society series. Rutgers University Press. New Brunswick, Nova Jersey.

Stepke FL 1998. Las ciencias sociales como discurso de la salud reproductiva. El ejemplo del climaterio feminino. Cadernos de Saúde Pública 14 (1):131-134.

Werthein S, Mallol S, Ferreira A \& Azcárate T 1999. De lãs paradojas de la madurez, pp. 12-17. Cuadernos Mujer Salud / Red Salud de las Mujeres latinoamericanas y del Caribe. Santiago, Chile.

Artigo apresentado em 1\%/7/2003

Aprovado em 8/9/2003

Versão final apresentada em 7/10/2003 